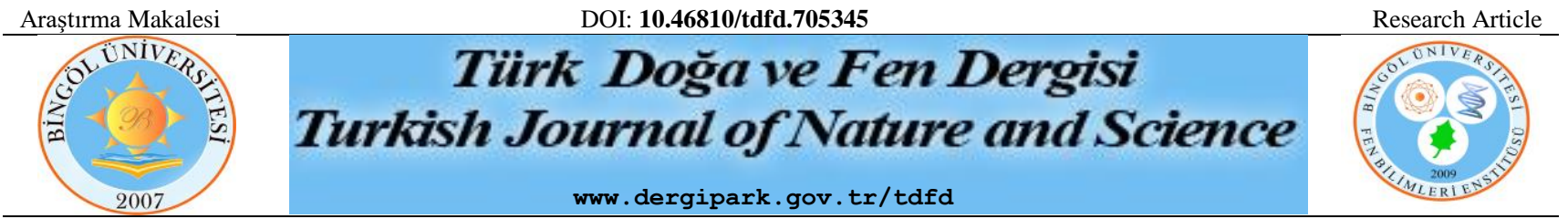

\title{
Toz Enjeksiyon Kalıplama Yöntemi ile Üretilen FeCo Alaşımlarının Mikroyapı ve Mekanik Özelliklerinin Araştırılması
}

\author{
Özgür ÖZGÜN ${ }^{1,2}$, Hamit Özkan GÜLSOY ${ }^{3^{*}}$ \\ ${ }^{1}$ Bingöl Üniversitesi, Mühendislik ve Mimarlık Fakültesi, Makine Mühendisliği Bölümü, 12000 Bingöl, Türkiye \\ ${ }^{2}$ Bingöl Üniversitesi, Sağlık Bilimleri Fakültesi, İş Sağlığı ve Güvenliği Bölümü, 12000 Bingöl, Türkiye \\ ${ }^{3}$ Marmara Üniversitesi, Teknoloji Fakültesi, Metalurji ve Malzeme Mühendisliği Bölümü, 34722 İstanbul, Türkiye \\ Özgür ÖZGÜN ORCID No: 0000-0003-3816-6746 \\ Hamit Özkan GÜLSOY ORCID No: 0000-0001-5366-5741
}

*Sorumlu yazar: ogulsoy@marmara.edu.tr

(Alınış: 18.03.2020, Kabul: 14.05.2020, Online Yayınlanma: 18.06.2020)

\begin{abstract}
Anahtar
Kelimeler

FeCo alaşımı,

Toz

enjeksiyon

kalıplama,

Mikroyapı,

Mekanik

özellikler

Öz: Bu çalışmada, Fe50Co0,2Si alaşımından toz enjeksiyon kalıplama tekniği ile metalik parça üretimi gerçekleştirilmiştir. Şekillendirme, çok bileşenli bir bağlayıcı sistemi kullanılarak gerçekleştirilmiştir. Şekillendirilen numuneler, uygulanan iki aşamalı bağlayıcı giderme işleminden sonra optimum sinterleme sıcaklığının belirlenmesi amacıyla farklı sıcaklıklarda sinterlenmiştir. Üretilen parçaların yoğunluk, mikroyapı ve mekanik özellikleri incelenmiştir. Yoğunluk ölçümleri ve mikroyapı incelemeleri, artan sinterleme sıcaklığının elde edilen bağıl yoğunluğu artırdı̆̆ını göstermiştir. Ancak, mikroyapı incelemelerinden bunun tane irileşmesine neden olduğu görülmüştür. Mikroyapının iki farklı fazdan oluştuğu tespit edilmiştir. Bu fazlardan biri $\mathrm{FeCo}$ katı çözeltisi iken diğer faz, üzerinde $(\mathrm{Fe}, \mathrm{Co})_{3} \mathrm{C}$ lamelleri bulunan FeCo katı çözeltisidir. Sertlik değerleri literatürde belirtilmiş olan değerlere yakın çıkmış olup, çekme testlerinde numuneler oldukça gevrek bir davranış sergilemiştir.
\end{abstract}

\section{Investigation of Microstructure and Mechanical Properties of FeCo Alloys Produced through Powder Injection Molding Method}

Keywords

FeCo alloy, Powder injection molding, Microstructure, Mechanical properties

\begin{abstract}
In this study, metallic parts were produced through powder injection molding technique from the Fe50Co0.2Si alloy. The shaping was carried out using a multi-component binder system. The shaped samples were sintered at different temperatures in order to determine the optimum sintering temperature after the two-step debinding process applied. The density, microstructure, and mechanical properties of the produced parts were examined. Density measurements and microstructure examinations have shown that increasing sintering temperature increases the relative density obtained. However, it has been observed from microstructure examinations that this causes grain coarsening. Microstructure of the parts produced consists of two different phases. While one of these phases is the FeCo solid solution, the other phase is the FeCo solid solution with lamellar $(\mathrm{Fe}, \mathrm{Co})_{3} \mathrm{C}$. The hardness values were close to the values specified in the literature, and the samples exhibited a rather brittle behavior in tensile tests.
\end{abstract}

bileşiği esaslı alaşımlardır [1]. Hacim merkezli kübik

\section{GİRİş}

Küçük bir dış alan uygulandığında kolaylıkla manyetik hale gelen veya manyetiklikleri giderilebilen soft manyetik malzemeler mühendislik malzemelerinin önemli bir sınıfını oluşturmaktadır [1]. Bu malzemeler metalik alaşımlar, intermetalikler ve seramikler olmak üzere genel olarak üç kategoriye ayrılabilmektedir [1,2]. Ticari manyetik malzemeler arasında en yüksek manyetik doygunluğa sahip olanları FeCo intermetalik
FeCo alaşımı, sahip olduğu yüksek manyetik doygunluk, düşük koersivite ve yüksek küri sıcaklığı nedeniyle manyetik kayıt cihazları, manyetik sensörler ve yüksek güçlü motorlar veya jeneratörlerde yaygın olarak kullanılan en önemli soft manyetik malzemelerden biridir [3-6]. Ancak, FeCo alaşımları çok gevrek olduğu için üretilmeleri oldukça zordur $[7,8]$. Sicak deformasyon ile şekillendirilebilmeleri için $900{ }^{\circ} \mathrm{C}$ 'nin üzerinde işlem yapılması gerekmektedir [9]. Soğuk şekillendirme esnasında deformasyon sertleşmesi 
nedeniyle sertliklerinde meydana gelen hızlı artış ve buna bağlı olarak meydana gelen çatlamalardan dolayı soğuk haddeleme ile şekillendirilmeleri oldukça güçtür [10]. Bunlara ek olarak küçük boyutlu ve karmaşık şekilli FeCo parçaların üretiminde döküm yöntemi uygun değildir [6].

Karmaşık şekilli parçaları yüksek ölçü hassasiyetinde üretmeyi sağlayan toz enjeksiyon kalıplama (TEK) yöntemi bir toz metalurjisi (T/M) tekniğidir. Bir T/M tekniği olmasına rağmen TEK, T/M'ndeki geleneksel presleme ve sinterleme aşamaları ile üretilen parçalara nazaran daha yüksek yoğunluğa ve mekanik özelliklere sahip parçaların üretilmesini mümkün kılar. Döküm ve talaşlı imalat yöntemleri ile kıyaslandığında TEK, daha karmaşık şekilli parçaların istenilen son geometri ve ölçülere sahip olacak şekilde daha ekonomik üretimine olanak tanır. Bunun yanında üretilen parçalar homojen kimyasal bileşim, ince tane yapısı, yüksek yüzey kalitesi gibi üstün özellikler sergilerler [11]. Son zamanlarda TEK metodu ile çeşitli alaşımlardan parça üretimine yönelik çok sayıda çalışma yapılmış ve başarılı sonuçlar elde edilmiştir [12-15].

$\mathrm{Bu}$ çalışmada, diğer üretim yöntemleri ile üretiminde çeşitli sınırlamalar bulunan FeCo alaşımından TEK metodu ile parça üretimi gerçekleştirilmiştir. Üretimde optimum sinterleme sıcaklığının tespit edilmesi amacıyla farklı sinterleme sıcaklıkları test edilmiştir. Üretilen parçaların yoğunluk, mikroyapı ve mekanik özellikleri incelenmiştir. Yoğunluk ölçümleri Arşimet prensibine göre gerçekleştirilmiştir. Mikroyap1, elektron mikroskobu (SEM) ve X-1şını analizi (XRD) teknikleri ile incelenmiştir. Sertlik ölçümleri ve çekme deneyleri uygulanarak üretilen malzemelerin mekanik özellikleri belirlenmiştir. Elde edilen sonuçlar FeCo alaşımları için literatürde verilen özelliklerle kıyaslanmıştır.

\section{MALZEME VE YÖNTEM}

Çalışmalarda Osprey firması tarafindan gaz atomizasyonu ile üretilmiş önalaşımlı Fe50Co0,2Si tozu kullanılmıştır. Toza ait SEM görüntüsü Şekil 1'de verilmiş olup tozun küresel şekilli parçacıklardan oluştuğu görülmektedir. Tozun parçacık boyutu 4-32 $\mu \mathrm{m}$ aralığındadır $\left(\mathrm{D}_{50}: 11,1 \mu \mathrm{m}\right)$.

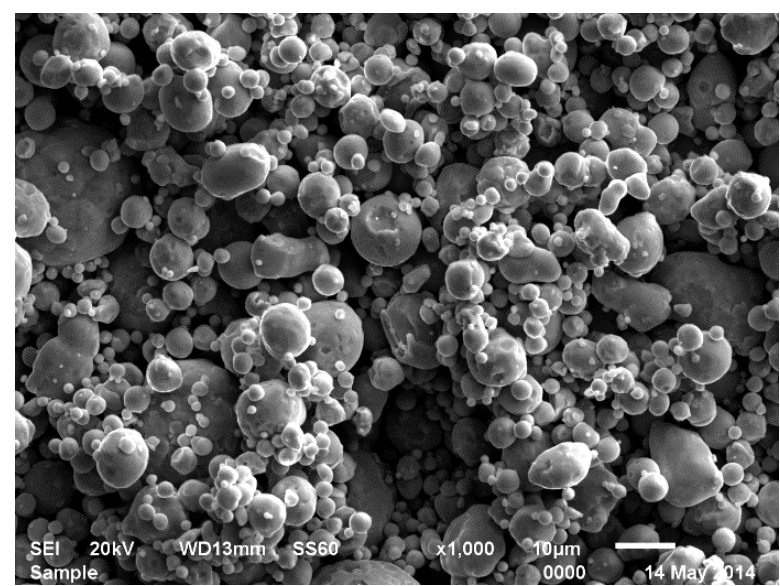

Şekil 1. Fe50Co0,2Si tozunun SEM görüntüsü
Fe50Co0,2Si tozunun polimerik malzemelerden oluşan çok bileşenli bir bağlayıcı sistemi (ağırlıç̧a \%69 parafin mum, $\% 20$ polipropilen, $\% 10$ brezilya mumu ve $\% 1$ stearik asit) ile $170{ }^{\circ} \mathrm{C}$ 'de karıştırılmasıyla hazırlanan besleme stoğu (hacimsel olarak \%62,5 toz) enjeksiyonla kalıplanarak standart çekme çubuğu formuna sahip numuneler şekillendirilmiştir. Kalıplama işlemi, enejeksiyon cihazının hazne ve nozül kısımları 170 ${ }^{\circ} \mathrm{C}$ 'ye 1sitılarak 12,5 MPa basınç ve 20 sn tutma süresi ile gerçekleştirilmiştir. Şekillendirilen numunelere solvent ( $60{ }^{\circ} \mathrm{C}^{\prime}$ ye 1 sıtıllmış heptan içerisinde 6 saat bekletme) ve ısıl bağlayıcı giderme işlemleri uygulanmış, bağlayıcısı giderilen numuneler vakum ortamında $1200-1350{ }^{\circ} \mathrm{C}$ arasındaki farklı sicaklıklarda 1 saat bekleme süresi ile sinterlenmiştir.

Sinterlenen numunelerin yoğunlukları Arşimet prensibine göre suya daldırma yöntemiyle belirlenmiştir. XRD analizi, Rigaku UltimaIV X-Ray Diffractometer cihazı ile $\mathrm{Cu}$ X-1şını tüpü $(\lambda=1,5405)$ kullanılarak $0,02 / 0,4$ saniye tarama hızı ile yapılmıştır. Mikroyapı incelemeleri için numuneler farklı zımparalama aşamalarından (220, 400, 600, 800, 1000 ve 1200 grit) geçirildikten sonra $1 \mu \mathrm{m}$ 'lik elmas süspansiyon ve çuha kullanılarak parlatılmıştır. Dağlama işlemi \%5'lik nital çözeltisi ile yapılmıştır. SEM incelemeleri JEOL marka JSM6510 model mikroskop ile gerçekleştirilmiştir. Enerji dağılım spektrometresi (EDS) analizleri SEM cihazına bağlı IXRF 550 marka sistem ile yapılmıştır. Sertlik ölçümleri Vickers yöntemine göre Emco-Test marka ve M1C 010 model cihaz kullanılarak $100 \mathrm{~g}$ yükün 10 sn uygulanmasıyla gerçekleştirilmiştir. Çekme deneyleri Shimadzu AG-IC $50 \mathrm{kN}$ model çekme cihazı kullanılarak oda sıcaklığında $0,5 \mathrm{~mm} / \mathrm{dk}$ sabit çekme hızı ile yapılmıştır.

\section{BULGULAR VE TARTIŞMA}

Şekil 2'de farklı sıcaklıklarda yapılan sinterleme işlemleri sonucunda numunelerde ulaşılan bağıl yoğunluk değerleri verilmiştir. Sinterleme sıcaklığının artmasıyla ulaşılan bağıl yoğunluk değerleri de artmıştır. Çalışmada kullanılan tozun teorik yoğunluğu $8,35 \mathrm{~g} . \mathrm{cm}^{-3}$ olarak hesaplanmıştır. En yüksek yoğunluk değeri 8,26 g.cm ${ }^{-3}$ olarak $1350{ }^{\circ} \mathrm{C}$ 'de sinterlenen numunede elde edilmiştir. $\mathrm{Bu}$ yoğunluk değerine karşılık gelen bağıl yoğunluk değeri \%98,82 olup T/M teknikleri ile üretilen malzemeler için oldukça yüksek bir değerdir. $1375{ }^{\circ} \mathrm{C}$ ve üzerinde yapılan sinterleme denemelerinde numunelerde ergimeler meydana gelmiş ve buna bağlı olarak şekil kayıpları oluşmuştur. Fe50Co alaşımından TEK yöntemi ile parça üretiminin gerçekleştirildiği bir çalışmada, 980 ${ }^{\circ} \mathrm{C}$ 'de sinterlenen numunelerde ortalama $8,03 \mathrm{~g} . \mathrm{cm}^{-3}$, $1330{ }^{\circ} \mathrm{C}$ 'de sinterlenen numunelerde ise ortalama 8,07 g.cm ${ }^{-3}$ yoğunluk değerleri elde edilmiştir [16]. Söz konusu çalışmaya [16] göre şimdiki çalışmada, 1300 ${ }^{\circ} \mathrm{C}$ 'de 7,92 g.cm ${ }^{-3}$ gibi daha düşük bir yoğunluk değeri elde edilmişken $1350{ }^{\circ} \mathrm{C}$ 'de gerçekleştirilen sinterleme ile daha yüksek bağıl yoğunluk elde edilmiştir. Buna rağmen iki çalışmada da elde edilen sonuçlar yakın olup, yoğunluk değerlerindeki küçük farklılıkların kullanılan tozların parçacık boyutları arasındaki farklılıktan kaynaklanabileceği düşünülmektedir. 


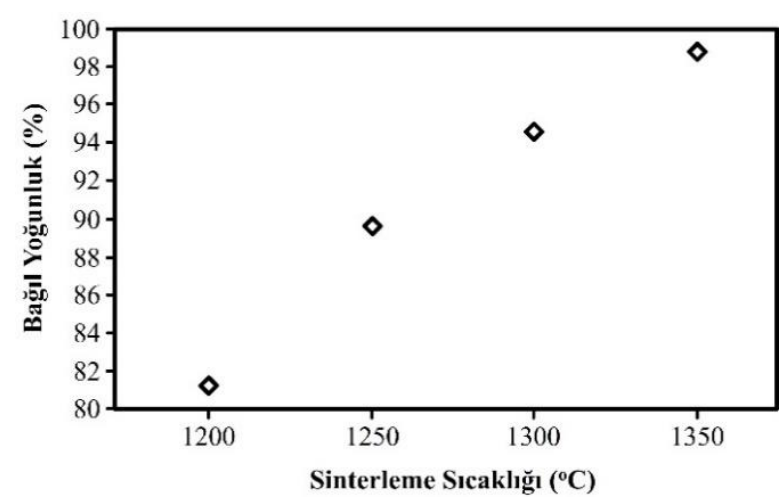

Şekil 2. Bağıl yoğunluk değerlerinin sinterleme sıcaklığ 1 ile değişimi

Yoğunluk ölçümlerini desteklemek amacıyla parlatma işlemi uygulanmış numunelerden dağlama öncesi alınan SEM görüntüleri Şekil 3'te verilmiştir. $1200{ }^{\circ} \mathrm{C}$ 'de sinterlenen numunenin görüntüsünde birbirleri ile bağlantılı, iri ve düzensiz şekilli gözenekler bulunduğu görülmektedir. Sinterleme sıcaklığındaki artışla birlikte, yoğunluk ölçümleri ile uyumlu olarak gözenek miktarı azalmıştır. Gözenek miktarındaki azalmanın yanında gözeneklerin boyutları da küçülmüştür. T/M ile üretilen malzemelerin mikroyapısında bulunan küresel geometrili gözeneklerin mekanik özellikler üzerindeki olumsuz etkilerinin düzensiz geometrili gözeneklere nazaran daha düşük olduğu bilinmektedir [17]. Bu açıdan bakıldığında $1300{ }^{\circ} \mathrm{C}$ ve altında gerçekleştirilmiş sinterlemeler sonucu oluşan gözenek geometrisinin mekanik özellikleri olumsuz etkileyeceği söylenebilir. $1350{ }^{\circ} \mathrm{C}$ 'de uygulanan sinterleme işlemi sonucu gözeneklerin küresel şekilli olduğu ve mekanik özellikler üzerinde meydana getirecekleri olumsuz etkinin daha az olacağ1 söylenebilir. TEK tekniği ile üretilen parçaların uygun sinterleme koşulları sağlandığında yapılarındaki gözenekleri daha küçük boyutlu ve küresel şekilli olması yöntemin bir avantajı olarak ortaya çıkmaktadır [18].

Şekil 4'te dağlama işleminden sonra alınmış SEM görüntüleri verilmiştir. $1250{ }^{\circ} \mathrm{C}$ 'de sinterlenen numuneye ait SEM görüntüsünde yoğunluk incelemelerinde ulaşılan sonuçlarla uyumlu olarak bol miktarda iri boyutlu ve düzensiz şekilli gözenek bulunduğu görülmektedir. Çalışmada parçacık boyutu küçük tozlar kullanılmış olmasına rağmen $1250{ }^{\circ} \mathrm{C}$ 'de sinterlenen numunenin yer yer $30-40 \mu \mathrm{m}$ aralığında iri boyutlu taneler içerdiği görülmektedir. $\mathrm{Bu}$, sinterleme işleminin tane irileşmesine neden olduğunu göstermektedir. 1350 ${ }^{\circ} \mathrm{C}$ 'de sinterlenen numunenin SEM görüntüsünde çok daha iri boyutlu taneler mevcut olup, artan sinterleme sıcaklığı ile tane irileşmesi daha belirgin bir hal almıştır. Silva et al. [16] tarafından yapılan çalışmada da sinterleme sıcaklığındaki artışla birlikte tane boyutu önemli ölçüde artmıştır. İnce taneli mikroyapıya sahip malzemelerin iri taneli olanlara kıyasla daha üstün fiziksel ve mekanik özellikler sergileyeceği iyi bilinen bir kaidedir [13-15]. Özellikle FeCo alaşımlarında hem mekanik özellikler hem de manyetik özellikler açısından tane boyutu önemli etkilere sahiptir [16, 19]. FeCo alaşımlarının mukavemetini artırmak amacıyla uygulanan tane inceltme, katı çözelti oluşturma ve çökelme sertleşmesi gibi işlemlerin manyetik özelliklerde azalmaya neden olduğu vurgulanmıştır [19].
Ticari alaşımlarda, düşük oranda karbon ile niyobyum ve tantal gibi karbür oluşturucu elementlerin eklenmesi sayesinde ince karbür çökeltileri oluşur. $\mathrm{Bu}$ ince karbürlerin varlığ 1 , son tavlama işlemi sırasında tane büyümesini kısitlar ve ince tane boyutunu koruyarak mukavemeti arttırır. Ancak, bu yöntemlerle daha yüksek mukavemet elde edilse de koersivitede de artış meydana gelmektedir [19].

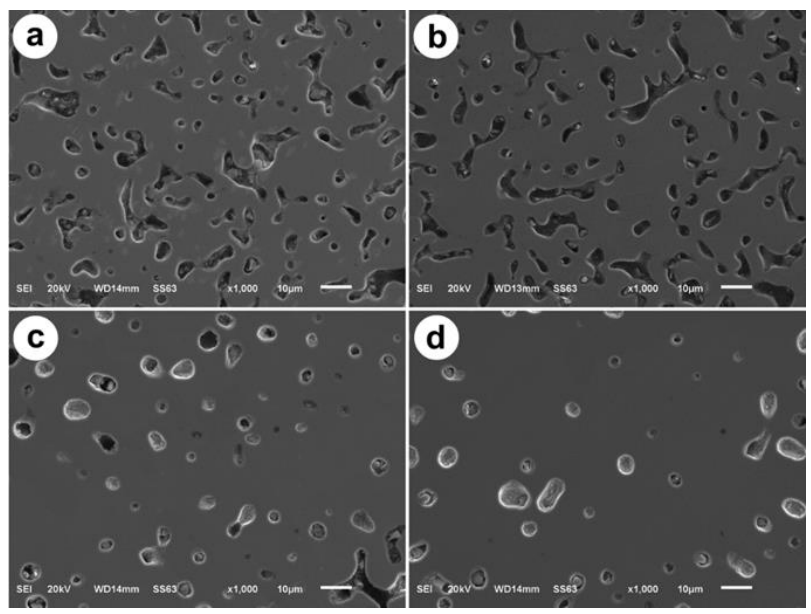

Şekil 3. Sinterleme sonrası parlatılmış numunelerden alınan SEM görüntüleri; a) $1200{ }^{\circ} \mathrm{C}$, b) $1250{ }^{\circ} \mathrm{C}$, c) $1300^{\circ} \mathrm{C}$, d) $1350{ }^{\circ} \mathrm{C}$

Şekil 4'te dağlama işleminden sonra alınmış SEM görüntüleri verilmiştir. $1250{ }^{\circ} \mathrm{C}$ 'de sinterlenen numuneye ait SEM görüntüsünde yoğunluk incelemelerinde ulaşılan sonuçlarla uyumlu olarak bol miktarda iri boyutlu ve düzensiz şekilli gözenek bulunduğu görülmektedir. Çalışmada parçacık boyutu küçük tozlar kullanılmış olmasına rağmen $1250{ }^{\circ} \mathrm{C}$ 'de sinterlenen numunenin yer yer $30-40 \mu \mathrm{m}$ aralığında iri boyutlu taneler içerdiği görülmektedir. $\mathrm{Bu}$, sinterleme işleminin tane irileşmesine neden olduğunu göstermektedir. 1350 ${ }^{\circ} \mathrm{C}$ 'de sinterlenen numunenin SEM görüntüsünde çok daha iri boyutlu taneler mevcut olup, artan sinterleme sıcaklığı ile tane irileşmesi daha belirgin bir hal almıştır. Silva et al. [16] tarafindan yapılan çalışmada da sinterleme sıcaklığındaki artışla birlikte tane boyutu önemli ölçüde artmıştır. İnce taneli mikroyapıya sahip malzemelerin iri taneli olanlara kıyasla daha üstün fiziksel ve mekanik özellikler sergileyeceği iyi bilinen bir kaidedir [13-15]. Özellikle FeCo alaşımlarında hem mekanik özellikler hem de manyetik özellikler açısından tane boyutu önemli etkilere sahiptir [16, 19]. FeCo alaşımlarının mukavemetini artırmak amacıyla uygulanan tane inceltme, katı çözelti oluşturma ve çökelme sertleşmesi gibi işlemlerin manyetik özelliklerde azalmaya neden olduğu vurgulanmıştır [19]. Ticari alaşımlarda, düşük oranda karbon ile niyobyum ve tantal gibi karbür oluşturucu elementlerin eklenmesi sayesinde ince karbür çökeltileri oluşur. $\mathrm{Bu}$ ince karbürlerin varlığ 1 , son tavlama işlemi sırasında tane büyümesini kısıtlar ve ince tane boyutunu koruyarak mukavemeti arttırır. Ancak, bu yöntemlerle daha yüksek mukavemet elde edilse de koersivitede de artış meydana gelmektedir [19]. 

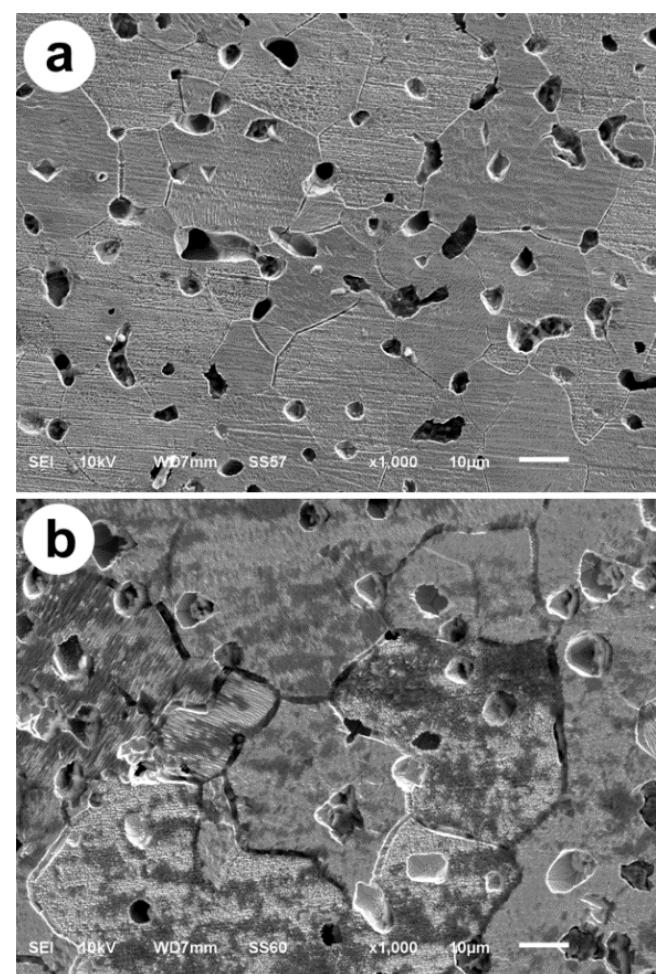

Şekil 4. Dağlanmış numunelerden alınan SEM görüntüleri; a) $1250{ }^{\circ} \mathrm{C}$, b) $1350{ }^{\circ} \mathrm{C}$

Şekil 5'te, başlangıç tozuna, $1200{ }^{\circ} \mathrm{C}$ 'de ve $1350{ }^{\circ} \mathrm{C}$ 'de sinterlenen numunelere uygulanan XRD analizlerinden elde edilen kırınım desenleri verilmiştir. Hem başlangıç tozunun hem de sinterlenmiş numunelerin kırınım desenleri malzemeyi oluşturan ana bileşenin Fe ve Co'ın meydana getirdiği $\alpha$ fazı olduğunu göstermektedir. Sinterleme işlemlerinin $\alpha$ fazının pik şiddetinde artışa neden olduğu gözlenmiştir. Başlangıç tozunun kırınım deseninde $65^{\circ} \quad 2 \theta$ açısında herhangi bir pik bulunmamasına rağmen sinterlenmiş numunelerin XRD desenlerinde söz konusu $2 \theta$ açısında çok belirgin bir pik oluşmuştur. Sinterleme sıcaklığının artması ile şiddeti artan bu pikin $(\mathrm{Fe}, \mathrm{Co})_{3} \mathrm{C}$ fazına ait olduğu tespit edilmiştir. Başlangıç tozu hiç karbon içermediği halde sinterleme işlemlerinden sonra $(\mathrm{Fe}, \mathrm{Co})_{3} \mathrm{C}$ fazının oluşması, bağlayıcı giderme işlemlerine rağmen mikroyapıda kalıntı karbon kaldığını göstermektedir. Li et al. [20] tarafindan döküm tekniği ile üretilen $(\mathrm{Fe} 0,5 \mathrm{Co} 0,5)_{\mathrm{x}}-(\mathrm{Mo} 0,1 \mathrm{C} 0,2 \mathrm{~B} 0,5 \mathrm{Si} 0,2)_{100-\mathrm{x}}(\mathrm{x}=95,90$ ve 85) alaşımlarında da $(\mathrm{Fe}, \mathrm{Co})_{3} \mathrm{C}$ fazının oluştuğu bildirilmiştir.

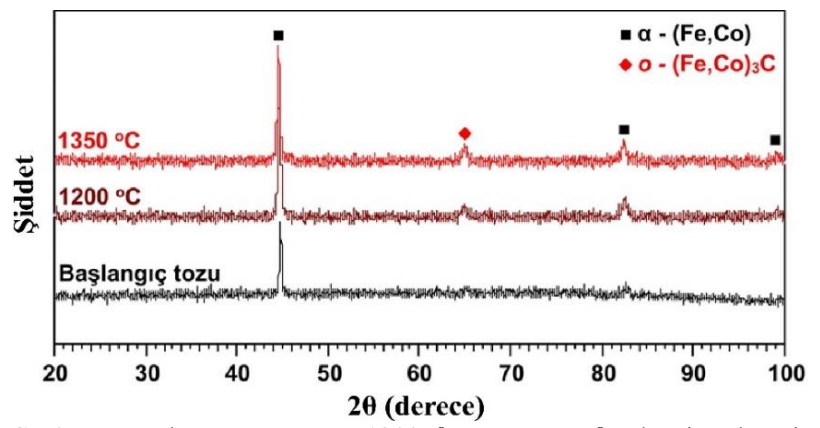

Şekil 5. Başlangıç tozunun, $1200{ }^{\circ} \mathrm{C}$ ve $1350{ }^{\circ} \mathrm{C}$ 'de sinterlenmiş numunelerin XRD analizi kırınım desenleri
Şekil 6'da $1350{ }^{\circ} C^{\prime}$ de sinterlenmiş numuneden alınmış SEM/EDS analizlerine ait görüntü ve kimyasal bileşim değerleri verilmiştir. SEM görüntüsünde malzemenin iki faklı faz tanelerinden oluştuğu görülmektedir. Yapılan EDS alan analizleri, 2 rakamı ile gösterilen alan analizinin alındığı fazın 1 rakamı ile gösterilen alan analizinin alındığı faza oranla çok daha yüksek karbon içerdiğini göstermiştir. Karbon oranı yüksek olan fazın lamelli bir yap1 sergilediği görülmektedir. XRD analizi ile malzeme içeisinde $(\mathrm{Fe}, \mathrm{Co})_{3} \mathrm{C}$ karbürlerinin oluşmuş olduğu belirtilmişti. $\mathrm{Bu}$ XRD bulgusuna dayanılarak yüksek karbon içeren fazın (Alan 2) Fe-Co katı çözeltisi üzerinde $(\mathrm{Fe}, \mathrm{Co})_{3} \mathrm{C}$ karbür lamellerinden oluşmuş olduğu söylenebilir. Yukarıda da belirtildiği gibi Fe-Co katı çözeltisi üzerinde bu karbürlerin oluşması, bağlayıcı giderme sürecinde tamamen uzaklaştırılamamış kalıntı karbon nedeniyle oluşmuştur. 3 rakamı ile gösterilen ve tane sınırında yer alan çökeltinin üzerinden alınan EDS nokta analizi, çökeltide yüksek oranda karbon bulunduğunu gösterdiğinden bu çökeltinin de Fe ve Co elementleri tarafindan oluşturulmuş bir karbür fazı olduğu açıktır. Fe ve Co elementleri tarafından oluşturulan bu karbürler tane içlerinde lameller, tane sınırlarında ise blok morfolojili çökeltiler halindedir. Li et al. [20], sert ve yumuşak fazların uygun hacimsel dağılım ve ortalama boyutlar ile mekanik özellikleri geliştirebileceğini belirtmişlerdir.

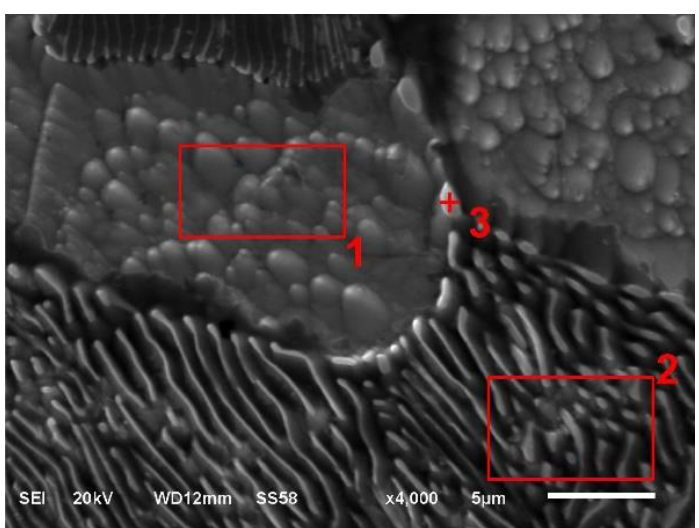

\begin{tabular}{|l|r|r|r|r|l|}
\hline Element & Alan 1 & Alan 2 & Nokta 3 & Birim & \\
\hline $\mathrm{C}$ & 2,135 & 14,736 & 16,671 & Wt.\% & \\
\hline $\mathrm{Fe}$ & 52,468 & 45,682 & 50,594 & Wt.\% & \\
\hline $\mathrm{Co}$ & 45,398 & 39,582 & 32,736 & Wt.\% & \\
\hline & 100,000 & 100,000 & 100,000 & Wt.\% & Toplam \\
\hline
\end{tabular}

Şekil 6. $1350{ }^{\circ} \mathrm{C}$ 'de sinterlenen numuneye ait SEM/EDS analizi

Şekil 7'de sinterleme sıcaklığına bağlı olarak üretilen numunelerden elde edilen sertlik değerleri verilmiştir. Sinterleme sıcaklığındaki artışla birlikte sertlik değerlerinin de arttığı görülmektedir. Bu durum, artan sinterleme sıcaklığı ile daha yüksek bağıl yoğunluk elde edilmesine bağlanmaktadır. Çünkü T/M teknikleri ile üretilen malzemelerde gözenek miktarındaki azalma ve yoğunluktaki artışın diğer mekanik özelliklerde olduğu gibi sertliği de artırdığı bilinmektedir [14]. Hosoda et al. [10] tarafından FeCo alaşımlarının sertliğinin soğuk şekillendirme ile artış gösterdiği ifade edilmiştir. Bununla birlikte henüz soğuk deformasyon uygulanmamış olan $\mathrm{FeCo}$ alaşımlarının sertliğinin yaklaşık 200 HV olduğu belirtilmiştir [10]. Şimdiki 
çalışmada, $1350{ }^{\circ} \mathrm{C}$ 'de gerçekleştirilen sinterleme işlemi ile Hosoda ve arkadaşları tarafından belirtilen sertlik değerine yakın sertlik değerleri elde edilmiştir.

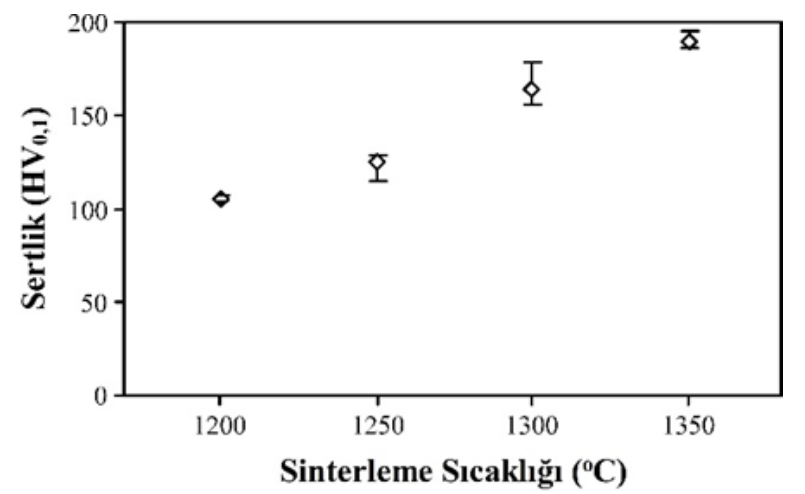

Şekil 7. Sinterleme sıcaklı̆̆ına bağlı olarak sertlik değişimi

Şekil 8'de farklı sinterleme sıcaklıklarının üretilen numunelerin çekme dayanımı ve sünekliğine etkileri görülmektedir. Sinterleme sıcaklığının artması çekme dayanımının artmasını sağlamıştır. En yüksek çekme dayanımı $184.7 \mathrm{~N} / \mathrm{mm}^{2}$ ile $1350{ }^{\circ} \mathrm{C}$ 'de sinterlenen numunede elde edilmiştir. Mikroyapı incelemelerinde, artan sinterleme sicaklığının tane irileşmesine neden olduğu belirtilmişti. Tane boyutunun artması, oda sıcaklığındaki mukavemet değerlerinin düşmesine neden olmaktadır [21,22]. Ancak, hem yoğunluk ölçümleri hem de mikroyapı incelemeleri, artan sinterleme sıcaklığının tane irileşmesine neden olmasına rağmen gözenek boyutunun ve miktarının azalmasını; gözenek geometrisinin küreselleşmesini sağladığını göstermişti. Tüm bunlar birlikte ele alındığında TEK yöntemi ile üretilen malzemelerin mukavemet değerleri üzerinde gözenek özelliklerinin tane boyutundan daha çok etki ettiği sonucu çıkarılabilir. Genel olarak tüm numunelerde çok düşük yüzde uzama değerleri elde edilmiştir. Daha yüksek oranda gözenek içermesine rağmen düşük sicaklıkta üretilen numunelerin daha yüksek uzama değerleri sergilediği görülmüştür. XRD analizi, artan sinterleme sicaklığı ile malzeme içerisindeki karbür lamellerinin oranının arttığını göstermiştir. Süneklikte meydana gelen düşüş karbür lamellerinin miktarının artmasına bağlanmaktadır.

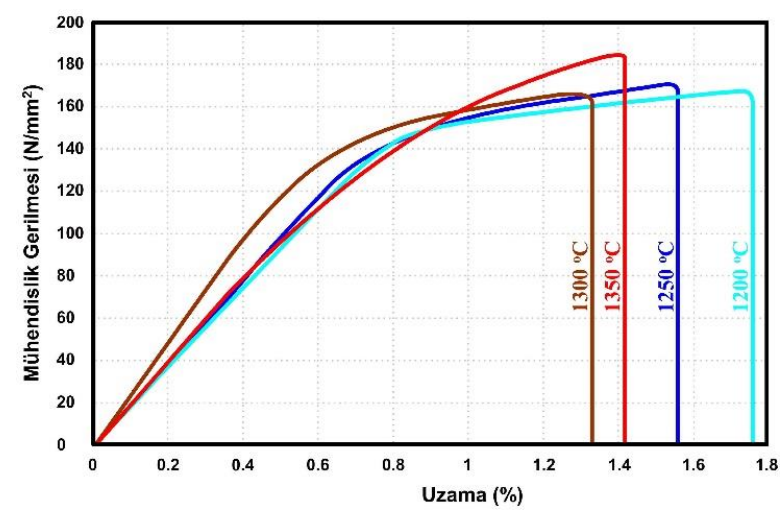

Şekil 8. Farklı sicaklıklarda sinterlenen numunelerin çekme diyagramları

Şekil 9'da 1200 ve $1350{ }^{\circ} C^{\prime}$ 'de sinterlenen numunelerin çekme deneyinden sonra kırılma yüzeylerinden faklı büyütme oranları ile alınan SEM görüntüleri verilmiştir.
$1200{ }^{\circ} \mathrm{C}$ 'de sinterlenen numunenin kırılma yüzeyinde yüksek oranda gözenek bulunduğu ve gözeneklerin birbirleriyle bağlantılı düzensiz geometrili gözenekler olduğu görülmektedir. $1350{ }^{\circ} \mathrm{C}$ 'de sinterlenen numunede ise çok daha küçük boyutlu ve küresel şekilli gözenekler bulunmaktadır. Hiçbir kırılma yüzeyinde gamze şeklinde çukurcuk (dimple) oluşumu bulunmamaktadır. Hem bu hem de çekme deneylerinden elde edilen yüzde uzama değerleri birlikte ele alındığında numunelerin gevrek kırılma sergiledikleri söylenebilir. Özellikle $1350{ }^{\circ} \mathrm{C}$ 'de sinterlenen numuneye ait görüntülerden kırılmanın tane içlerinde gerçekleştiği anlaşılmaktadır. Literatürde FeCo alaşımlarının oldukça kırılgan oldukları belirtilmiş olup $[7,8]$, TEK yöntemi ile üretilen numunelerde de durum değişmemiştir. $\mathrm{Bu}$ gevrekliğin giderilebilmesi için $\mathrm{FeCo}$ alaşımlarına çeşitli alaşım elementleri ilave edilebilmekte ve/veya isıl işlemler yapılabilmektedir $[4,19]$. Ancak bu, sünekliği artırmasına rağmen manyetik özelliklerde düşüşe neden olmaktadır [16].
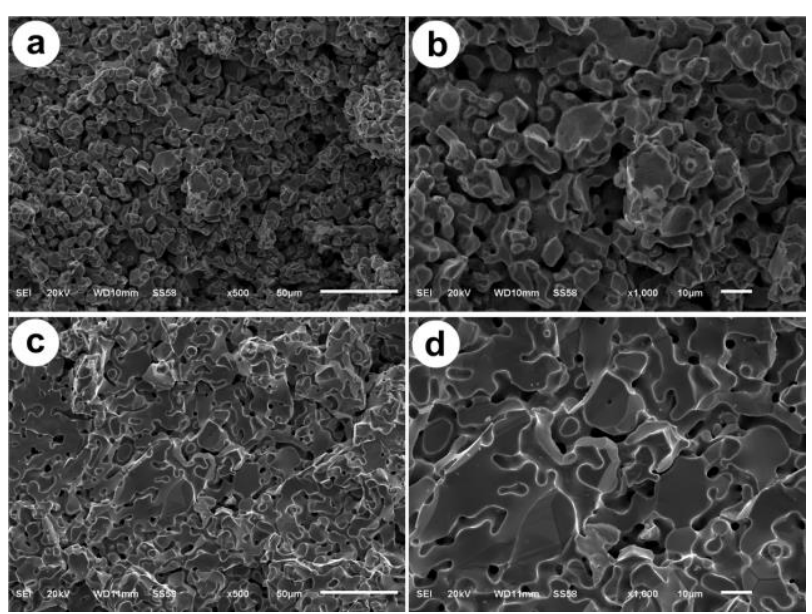

Şekil 9. Kırılma yüzeylerinden farklı büyütmelerle alınan SEM görüntüleri; a) ve b) $1200{ }^{\circ} \mathrm{C}$, c) ve d) $1350{ }^{\circ} \mathrm{C}$

\section{SONUÇLAR}

Fe50Co0,2Si alaşımından TEK yöntemi ile parça üretimi gerçekleştirilmiştir. Üretimde farklı sinterleme sıcaklıkları denenmiş; üretilen numuneler yoğunluk ölçümleri, mikroyapı incelemeleri ve mekanik testlerle karakterize edilmiştir. Sinterleme sıcaklığının artması ile daha yüksek yoğunluk değerlerine ulaşılmıştır. En yüksek bağıl yoğunluk $\% 98,82$ olarak $1350{ }^{\circ} \mathrm{C}$ 'de gerçekleştirilen sinterleme işlemi ile elde edilmiştir. Sinterleme sıcaklığının artması yoğunluk değerlerini artırırken tane irileşmesine neden olmuştur. Artan bağ 11 yoğunluk değerleri, daha yüksek sertlik ve çekme dayanımı elde edilmesini sağlamıştır. Bağlayıcı giderme işlemi ile tamamen uzaklaştırılamayan kalıntı karbon nedeniyle mikroyapıda FeCo katı çözelti fazına ek olarak $(\mathrm{Fe}, \mathrm{Co})_{3} \mathrm{C}$ lamellerini içeren ikinci bir faz oluşmuştur. Üretilen numuneler, çekme deneylerinde tane içinden gevrek bir şekilde kırılmış ve oldukça düşük uzama değerleri göstermişlerdir. 


\section{KAYNAKLAR}

[1] Sundar RS, Deevi C. Soft magnetic FeCo alloys: alloy development, processing, and properties. Int Mat Rev. 2005;50(3):157-92.

[2] Abraham T. Magnets and magnetic materials: A technical economic analysis. JOM 1995;47(1):168.

[3] Daoush WM. Processing of FeCo nanosized softmagnetic material by powder metallurgy technique. Mater Sci Forum 2007;558-559:707-15.

[4] Sourmail T. Near equiatomic FeCo alloys: Constitution, mechanical and magnetic properties. Prog Mater Sci. 2005;50:816-80.

[5] Díaz-Ortiz A, Drautz R, Fähnle M, Dosch H, Sanchez JM. Structure and magnetism in bcc-based iron-cobalt alloys. Phy Rev. B 2006;73:224208.

[6] Yang B, Cao Y, Zhang L, Li RF, Yang XY, Yu RH. Controlled chemical synthesis and enhanced performance of micron-sized FeCo particles. J Alloys Compd. 2014;615:322-6.

[7] Gilles R, Hofmann M, Johnson F, Gao Y, Mukherji D, Hugenschmidt C, Pikart P. Analysis of antiphase domain growth in ternary FeCo alloys after different cooling rates and annealing treatments using neutron diffraction and positron annihilation. J Alloys Compd. 2011; 509:195-9.

[8] Hasani S, Shamanian M, Shafyei A, Behjati P, Nezakat M, Fathi-Moghaddam M, Szpunar JA. Influence of annealing treatment on micro/macrotexture and texture dependent magnetic properties in cold rolled FeCo-7.15V alloy. J Magn Magn Mater. 2015;378:253-60.

[9] Zhao L, Baker I. Extrusion processing of FeCo. J Mater Sci. 1994;29:742-8.

[10] Hosoda H, Miyazaki S, Inoue K, Fukui T, Mizuuchi K, Mishima Y, Susuku T. Cold rolling of B2 intermetallics. J Alloys Comp. 2000;302:26673.

[11] German RM. Powder Injection Molding. In ASM Handbook: Powder Metal Technologies and Applications. 1998. p. 831-51.

[12] Ozgun O, Yilmaz R, Gulsoy HO, Findik F. Toz enjeksiyon kalıplama yöntemi ile üretilen 718 süperalaşım parçaların kırılma tokluğu ve darbe dayanımı özellikleri. $\operatorname{Tr}$ Doğa ve Fen Derg. 2015;4(1):1-7.

[13] Gulsoy HO, Ozgun O, Bilketay S. Powder injection molding of Stellite 6 powder: Sintering, microstructural and mechanical properties. Mater Sci Eng A 2016;651:914-24.

[14] Ozgun O, Gulsoy HO, Findik F, Yılmaz R. Microstructure and mechanical properties of injection moulded Nimonic-90 superalloy parts. Powder Metall. 2012;55:405-14.

[15] Ozgun O, Gulsoy HO, Yilmaz R, Findik F. Injection molding of nickel based 625 superalloy: Sintering, heat treatment, microstructure and mechanical properties. J Alloys Compd. 2013;546:192-207.

[16] Silva A, Lozano JA, Machado R, Escobar JA, Wendhausen PAP. Study of soft magnetic iron cobalt based alloys processed by powder injection molding. J Magn Magn Mater. 2008;320(14):e393e6.

[17] Simchi A. Densification and microstructural evolution during co-sintering of Ni-base superalloy powders. Metall Mater Trans A 2006;37: 2549-57.

[18] Vervoort PJ, Vetter R, Duszczyk J. Overview of powder injection molding. Adv Perform Mater. 1996;3:121-51.

[19] Sundar RS, Deevi SC. Influence of alloying elements on the mechanical properties of $\mathrm{FeCo}-\mathrm{V}$ alloys. Intermetallics 2004;12:921-7.

[20] Li R, Liu G, Stoica M, Eckert J. FeCo-based multiphase composites with high strength and large plastic deformation. Intermetallics 2010;18(1):1349.

[21] Savaşkan T. Malzeme Bilimi ve Malzeme Muayenesi. 6. Bask1 Trabzon: Celepler Matbaacilık; 2012.

[22] Callister WD, Rethwisch DG. Materials Science and Engineering: An Introduction. 8th ed. USA: John Wiley \& Sons; 2009. 